\title{
Tuning Class E Inverters Applied In Inductive Links Using Saturable Reactors
}

\author{
Samer Aldhaher, Patrick C. K. Luk, Senior Member, IEEE James F. Whidborne, Senior Member, IEEE
}

\begin{abstract}
This paper investigates the performance of Class $\mathbf{E}$ inverters used in wireless power transfer applications based on resonant inductive coupling. The variations in the load and the distance between the coils cause Class $\mathbf{E}$ inverters to operate in non-optimal switching conditions, which result in inefficient operation and can lead to permanent damage to its switching transistor. Therefore, a novel approach to tune Class $\mathbf{E}$ inverters electronically is proposed. The tuning method relies on saturable reactors to ensure that the inverter operates at optimal switching conditions regardless of variations in the load and the distance between the coils. In addition, a more accurate model of inductive links is presented in order to provide a better understanding of the major power losses in resonant inductive links. Experimental results are presented to confirm the improved accuracy of the inductive link model and the validity of the tuning method.
\end{abstract}

Index Terms-Inductive power transmission, Coupling circuits, Resonant inverters, Tunable circuits and devices

\section{INTRODUCTION}

Wireless power transfer (WPT) based on resonant inductive links has received a lot of attention recently to provide power to a wide variety of applications such as portable handheld devices, medical implants [1], [2], lighting [3] and charging of electric vehicles [4], [5]. Increasing the range and power transfer capability of WPT systems requires higher resonant frequencies and more powerful primary coil drivers. The Class E inverter, first introduced by the Sokals in 1975 [6], is an example of such a design that can match the requirements of WPT systems by having the ability to deliver large power levels at higher switching frequencies. Class E inverters feature simplicity, low component count and can be constructed using a single switching transistor and therefore require less complicated gate driving circuitry and timing control. Hence, the Class E inverter is suited to be used as the primary coil driver in resonant inductive links [7]-[15].

In general, Class $\mathrm{E}$ inverters are sensitive to variations in the load impedance [16]. Small deviations from the optimum load value would cause the inverter to operate in non-optimal and inefficient switching conditions, whereas large deviations could cause permanent damage to its switch. In resonant inductive links, the variations in the load or in the distance between the primary and secondary coils cause the reflected impedance seen by the primary coil driver to vary significantly. This limits the operation of Class E inverters in resonant inductive links to a narrow range of load and distance values. A significant benefit for a WPT system would be the ability to maintain optimum power transfer and efficiency of the

Manuscript received XXX xx, 2013; revised XX xx, 2013; accepted XXX xx 2013.

The authors are with the School of Engineering, Cranfield University, Bedford, MK43 0AL, UK e-mail: s.aldhaher@cranfield.ac.uk. primary coil driver over a useful load and distance ranges. This would increase the scope of WPT applications and allow novel applications such as dynamic grid-to-vehicle charging and vehicle-to-vehicle charging to be implemented. To Achieve this, the Class E inverter would need to be tuned as the load and distance vary.

Tuning methods based on impedance transformation [17][20], impedance network switching [21], [22] and phase control and load modulation [23]-[26] have been proposed. These methods allow the Class E inverter to operate in optimal switching conditions, achieving zero-voltage (ZVS) and zerovoltage derivative (ZVDS) switching regardless of the load value. However, these methods may not be applicable to resonant inductive links due to the complexity of the load and the reflected impedances. Furthermore, including additional components in series with the primary coil is undesirable since this increases the equivalent series resistances (ESR) and hence an increase in ohmic power losses. It should be noted that in recent publications in high power resonant inductive links [1], [27]-[30], only the ESR of the coils is included in the modelling of the inductive link, whereas the ESR of the resonant capacitors is ignored.

This paper investigates the effect of changing the load value and the distance between the coupled coils in resonant inductive links, as well as the effect of these changes on the performance of Class $\mathrm{E}$ inverters based on an improved circuit representation of the inductive link. A novel method is proposed to electronically tune the Class $\mathrm{E}$ inverter by using a saturable reactor to ensure that the inverter operates at optimum switching conditions for any load and distance values, while maintaining a relatively constant power transfer and efficiency over a certain load and distance ranges.

This paper is organised as follows. Section II provides a brief review of the theory behind resonant inductive links, discusses the operation in near resonance and the factors that affect the value of the reflected impedance. Section III shows the effect of the load and the mutual inductance between the coils on the performance of Class $\mathrm{E}$ inverters and describes the proposed tuning method. Section IV-A describes the experimental setup and the validation process of the proposed method. Section IV-B includes the experimental results and discussion. Finally Sec. V provides the conclusions and future work.

\section{INDUCTIVE LiNK MODELLING}

\section{A. Resonant Inductive Coupling Review}

A resonant inductive link consists of a primary coil driven by a sinusoidal current at a certain frequency and a secondary 


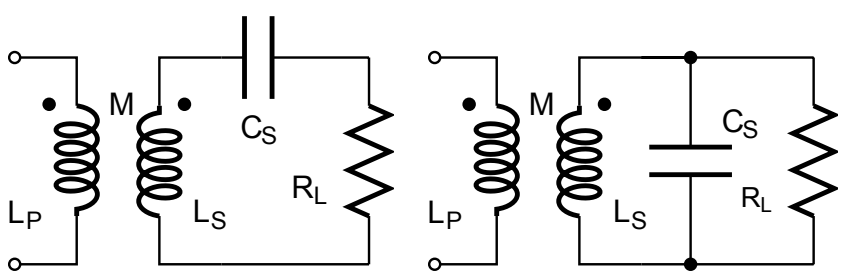

Fig. 1. Resonance configurations in the secondary coil (a) Series. (b) Parallel

coil tuned to that frequency. Both coils are assumed to be loosely coupled. The secondary coil, to which the load is connected, can be tuned by adding capacitance either in series or in parallel. For high frequencies of up to several megahertz, the operating frequency can be set to be equal to the selfresonant frequency of the secondary coil which is due to the stray capacitance of the coil and its self-inductance [31] [33]. Deciding on whether to connect a series or parallel capacitor to the secondary coil depends on the load value, the mutual inductance and the resonant frequency as described in [34]. A series capacitor is preferred if the load's resistance is greater than the secondary coil's reactance, whereas a parallel capacitor is preferred if the load's resistance is less than the reactance of the secondary coil. Figure 1 shows both series and parallel secondary resonance configurations.

The main aim of resonance, whether in a series secondary resonant coil or a parallel secondary resonant coil, is to maximise the reflected impedance seen by a power source connected to the primary coil. Therefore, power can be delivered more efficiently to a load at larger separation distances. In a similar manner, adding a capacitor in series or parallel with the primary coil, which is often referred to as a compensation capacitor, creates resonance and eliminates its impedance, thus allowing more power to be delivered to the load. A series capacitor is used if the power source is a voltage source, whereas a parallel capacitor is used if the power source is a current source.

Since the primary and secondary coils in inductive links may have different different dimensions, it is useful to define a dimensionless parameter that describes the amount of magnetic flux the links the two coils together. This parameter is referred to as the coupling coefficient and is defined as:

$$
k \equiv \frac{M}{\sqrt{L_{P} L_{S}}}
$$

where $L_{P}$ is the inductance of the primary coil, $L_{S}$ is the inductance of the secondary coil and $M$ is the mutual inductance between the two coils.

\section{B. Near Resonance Operation}

Consider the secondary resonant circuit with a parallel capacitor shown in Fig. $1 \mathrm{~b}$, the total reflected impedance $Z_{\text {Ref }}$ seen by a power source connected to the primary coil is equal to

$$
\begin{gathered}
Z_{R e f}\left(k, \omega, R_{L}\right)=\frac{X_{M}^{2}}{j X_{L_{S}}+\frac{-j X_{C_{S}} R_{L}}{R_{L}-j X_{C_{S}}}} \\
=\frac{X_{M}^{2}\left(R_{L}^{2}+X_{C_{S}}^{2}\right)}{j X_{L_{S}} R_{L}^{2}+j X_{L_{S}} X_{C_{S}}^{2}-j X_{C_{S}} R_{L}^{2}+X_{C_{S}}^{2} R_{L}}
\end{gathered}
$$

where $X_{M}$ is the reactance of the mutual inductance, $X_{L_{S}}$ is the reactance of the secondary coil, $X_{C_{S}}$ is the reactance of the parallel capacitor and $R_{L}$ is the load resistance. For resonance, the imaginary term in 2 should be zero

$$
X_{C_{S}}^{2} X_{L_{S}}-X_{C_{S}} R_{L}^{2}+X_{L_{S}} R_{L}^{2}=0
$$

giving the capacitor's reactance

$$
X_{C_{S}}=\frac{R_{L}^{2}-\sqrt{R_{L}^{4}-4 X_{L_{S}}^{2} R_{L}^{2}}}{2 X_{L_{S}}}
$$

and the resonant capacitance is equal to

$$
C_{S}=\frac{2 X_{L_{S}}}{\omega R_{L}^{2}\left(1-\sqrt{1-\frac{4 X_{L_{S}}^{2}}{R_{L}^{2}}}\right)}=\frac{1+\sqrt{1-\frac{16 \pi^{2} f^{2} L_{S}^{2}}{R_{L}^{2}}}}{8 \pi^{2} f^{2} L_{S}} .
$$

Note that the resonant capacitance depends on the load resistance. From Eq. 5, the resonant frequency for a certain inductor with a parallel capacitor and resistor is equal to

$$
f=\frac{1}{2 \pi} \sqrt{\frac{1}{L_{S} C_{S}}-\frac{1}{C_{S}^{2} R_{L}^{2}}} .
$$

From a practical point of view it is not feasible to change the parallel capacitor as the load changes. Therefore, the secondary coil will have to operate at a frequency close or near to its resonant frequency. This is achieved by keeping the parallel capacitor constant with a reactance equal to the reactance of the secondary coil at resonance. Due to the inverse squared term of the load resistance in Eq. 6, it can be assumed that the secondary coil will be operating in resonance with the primary coil for high load resistance values only.

\section{Reflected Impedances}

In Fig. 2, the reflected impedance of a secondary coil with a parallel capacitor that is operating at near resonance is given by

$$
\begin{gathered}
Z_{R e f}\left(k, \omega, R_{L}\right)=\frac{X_{M}^{2}}{r_{L_{S}}+j X_{L_{S}}+\frac{R_{L}\left(r_{C_{S}}-j X_{C_{S}}\right)}{R_{L}+r_{C_{S}}-j X_{C_{S}}}} \\
=\frac{X_{M}^{2}\left(R_{L} a+r_{L_{S}} a-j X_{C_{S}} a-j R_{L} b-j r_{C_{S}} b-X_{C_{S}} b\right)}{a^{2}+b^{2}}
\end{gathered}
$$

where $r_{L_{S}}$ and $r_{C_{S}}$ are the ESR of the secondary coil and the parallel capacitor respectively, and

$$
\begin{aligned}
a & =R_{L}\left(r_{L_{S}}+r_{C_{S}}\right)+r_{L_{S}} r_{C_{S}}+X_{L_{S}} X_{C_{S}} \\
b & =R_{L}\left(X_{L_{S}}-X_{C_{S}}\right)+X_{L_{S}} r_{C_{S}}-X_{C_{S}} r_{L_{S}} .
\end{aligned}
$$




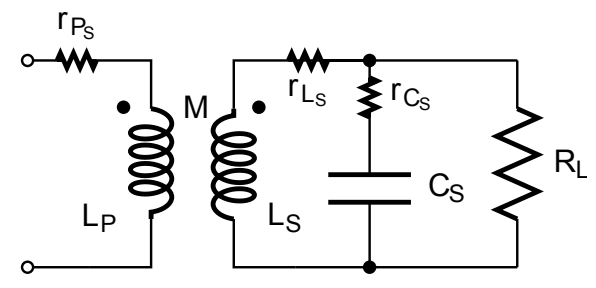

Fig. 2. A parallel resonant secondary with non ideal components

Equation 7 can be represented in a simplified form by isolating the reflected impedances that correspond to the inductance of the coil, the parallel capacitor, the ESRs and the load resistance as follows

$$
\begin{array}{r}
Z_{R e f}\left(k, \omega, R_{L}\right)=R_{R e f}\left(k, \omega, R_{L}\right)+r_{R e f}\left(k, \omega, R_{L}\right)+ \\
\ldots j X_{R e f}\left(k, \omega, R_{L}\right)+j x_{R e f}\left(k, \omega, R_{L}\right)
\end{array}
$$

where $R_{R e f}$ is the real part of the reflected impedance corresponding to the load and is equal to:

$$
R_{R e f}\left(k, \omega, R_{L}\right)=\frac{X_{M}^{2} X_{C_{S}}^{2} R_{L}}{a^{2}+b^{2}} .
$$

Resistance $r_{\text {Ref }}$ is the real part of the reflected impedance corresponding to the ESR of the coil and the capacitor and is equal to

$$
\begin{gathered}
r_{R e f}\left(k, \omega, R_{L}\right)= \\
\frac{X_{M}^{2}\left(R_{L}^{2}\left(r_{L_{S}}+r_{C_{S}}\right)+2 R_{L} r_{L_{S}} r_{C_{S}}+R_{L} r_{C_{S}}^{2}+\ldots\right.}{a^{2}+b^{2}} \\
\left.\ldots r_{L_{S}} r_{C_{S}}^{2}+X_{C_{S}}^{2} r_{L_{S}}\right) .
\end{gathered}
$$

Reactance $X_{\text {Ref }}$ is the imaginary part of the reflected impedance which corresponds to the coil, the parallel capacitor and resistance and is equal to

$$
X_{R e f}\left(k, \omega, R_{L}\right)=\frac{X_{M}^{2}\left(R_{L}^{2}\left(X_{C_{S}}-X_{L_{S}}\right)-X_{L_{S}} X_{C_{S}}^{2}\right)}{a^{2}+b^{2}} .
$$

Reactance $x_{R e f}$ is the imaginary part of the reflected impedance corresponding to the ESR of the coil and the capacitor and is equal to

$$
x_{R e f}\left(k, \omega, R_{L}\right)=\frac{X_{M}^{2}\left(2 X_{C_{S}} R_{L} r_{C_{S}}-X_{L_{S}} r_{C_{S}}^{2}\right)}{a^{2}+b^{2}} .
$$

\section{Load and Frequency Variation Effects On The Reflected Impedances}

This section shows the effect of varying the load and the frequency on the total reflected impedance based on an implemented inductive link. The primary coil consists of two layers each having four turns of 18 AWG magnet wire and a diameter of $8 \mathrm{~cm}$. The secondary coil consists of a single layer of four turns of 20 AWG magnet wire with a diameter of $7 \mathrm{~cm}$. The measured inductance and ESR of both coils are plotted in Fig. 3. The measured mutual inductances and the calculated coupling coefficients as a function of the separation distance and frequency are plotted in Fig. 4. Both self and

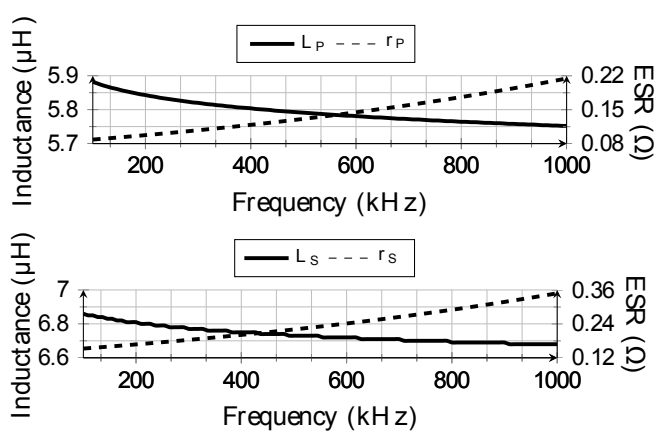

Fig. 3. Measured self inductances and ESR of the primary and secondary coils (10kHz steps)

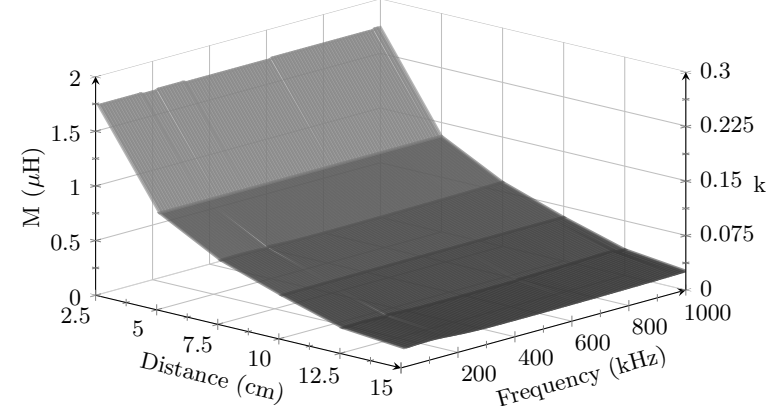

Fig. 4. Measured mutual inductance $(2.5 \mathrm{~cm} \& 10 \mathrm{kHz}$ steps $)$

mutual inductance measurements were taken using a PSM1700 PsimetriQ phase sensitive multimeter. The dimensions of the designed coils were chosen to achieve a higher coupling coefficient at large separation distances. This allows power to be transferred efficiently and therefore the operation of the WPT system can be validated at a wide operation range. In addition, the measurement error of the separation distance is reduced as the coils are moved further or closer apart. Using Equations 11 to 14 , the values of $R_{R e f}$ and $r_{R e f}$ are calculated as $R_{L}$ and the frequency are swept from $0 \Omega$ to $2 \mathrm{k} \Omega$ and $100 \mathrm{kHz}$ to $1 \mathrm{MHz}$ respectively. Figure 5 shows the calculated reflected resistances of the load and ESRs as a function of the load and resonant frequency. The resonant capacitor's ESR and reactance are set to be equal to the inductor's ESR and reactance respectively for each frequency according to the equation below:

$$
C=\frac{1}{\omega^{2} L_{S}}=\frac{1}{(2 \pi)^{2} f^{2} L_{S}} .
$$

It can be noticed from Fig. 5 that at low load values, or higher load resistance, and high resonant frequencies, $R_{R e f}$ is larger than $r_{R e f}$ and most of the power that is received in the secondary coil will be dissipated in the load. As the load and resonant frequency decrease, $r_{R e f}$ has a more significant value and a large portion of the power received in the secondary coil will be dissipated as heat in the ESRs of the coil and the parallel capacitor. The maximum difference between $R_{R e f}$ and $r_{R e f}$ corresponds to the maximum power efficiency of the secondary coil side. Consequently, it can be concluded that power can be transferred at higher efficiencies and large separation distances at low load values and high 


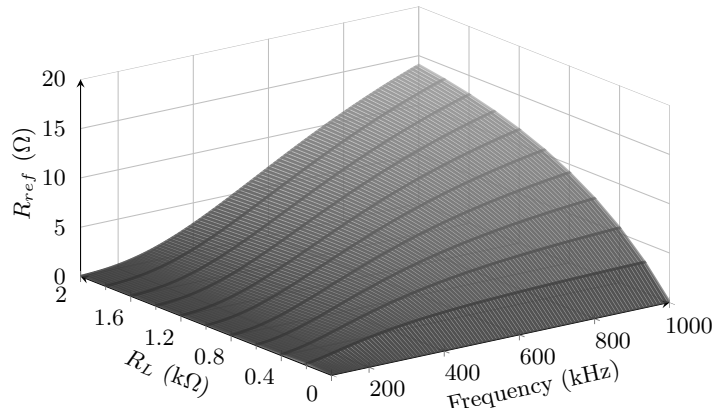

(a) $R_{R e f}$

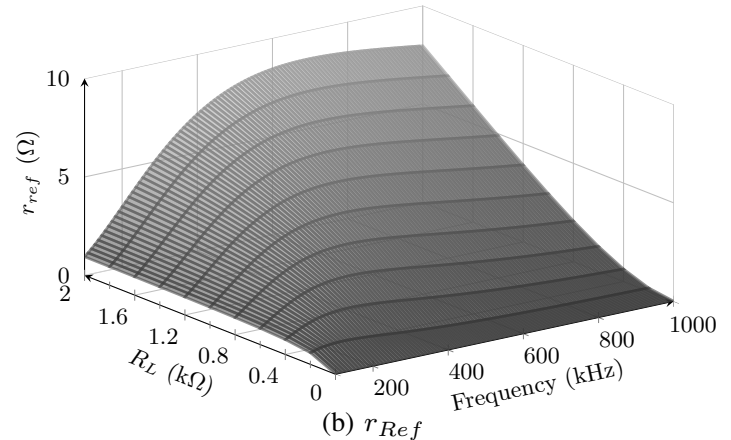

Fig. 5. The calculated reflected resistance $R_{R e f} \& r_{R e f}$ as a function of load resistance and resonant frequency

resonant frequencies. However, due to practical limitations, the maximum frequency that can be used is limited by the losses in the MOSFET gate driving circuitry and the switching losses in the primary coil driver. Figure 6a shows the total values of the calculated reflected impedances $R_{R e f}$ and $r_{R e f}$ based on Eqs. $11 \& 12$ when the operating frequency shifts from the resonant frequency of the secondary coil. The measured total reflected impedances is plotted in Fig. $6 \mathrm{~b}$ for comparison. It assumed that the resonant frequency is fixed at $800 \mathrm{kHz}$ and the distance between the coils is $5 \mathrm{~cm}$ corresponding to a coupling coefficient of 0.11 . The calculated total reflected impedances values are in good agreement with those measured.

\section{Class E INVERTER Optimization}

\section{A. Performance Investigation}

The Class E inverter was chosen as the driver for the primary coil due to its simplicity, high efficiency and high power delivering capability. The circuit diagram of a Class E inverter including the coupled coils is shown in Fig. 7. Detailed description and analysis of Class $\mathrm{E}$ inverters or amplifiers are well documented in the literature [6], [35]-[41]. The addition of capacitor $C_{P}$ in parallel with the primary coil $L_{P}$ forms an impedance transformer. Since the reflected impedance in inductive links is much lower than the actual load value, it is therefore transformed into a larger impedance to reduce the current levels throughout the inverter. This allows the Class E inverter to operate at a higher efficiency and less current stresses. The design procedure begins with a predetermined resonant frequency, a primary coil inductance and a reflected impedance $Z_{R e f}$. The transformed impedances due to $C_{P}$ are

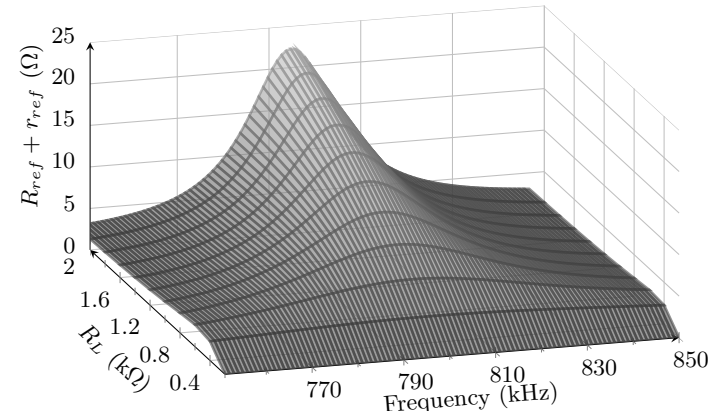

(a) The calculated total reflected impedances

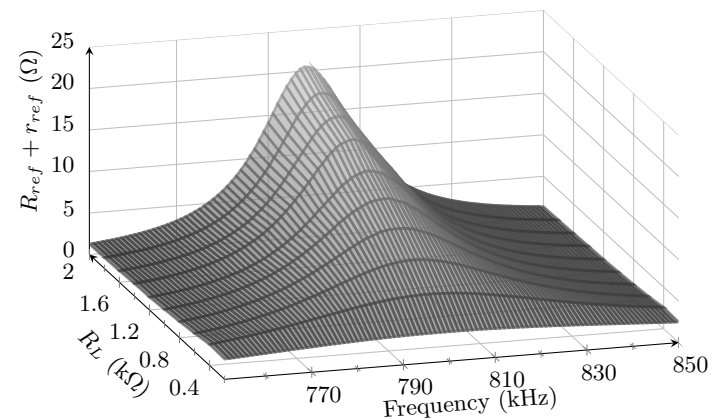

(b) The measured total reflected impedances (200 $\Omega$ and $10 \mathrm{kHz}$ steps)

Fig. 6. The total reflected impedance for a fixed resonant frequency of $800 \mathrm{kHz}$ as a function of frequency and load resistance

calculated as follows

$$
\begin{gathered}
Z_{T}\left(k, \omega, R_{L}\right)=\frac{-j X_{C_{P}}\left(r_{L_{P}}+Z_{R e f}\right)}{-j X_{C_{P}}+r_{L_{P}}+Z_{R e f}} \\
R_{T}\left(k, \omega, R_{L}\right)=\operatorname{Re}\left(Z_{T}\right) \\
L_{T}\left(k, \omega, R_{L}\right)=\frac{\operatorname{Im}\left(Z_{T}\right)}{\omega}
\end{gathered}
$$

where $Z_{T}$ is the total transformed impedance which includes the total reflected impedance and the ESR of the primary coil. Resistance $R_{T}$ is the real part of the total transformed impedance which represents the total load to the inverter. Inductance $L_{T}$ is the total inductance seen by the inverter which includes the inductance of the primary coil and that of the reflected impedance. The values of the components of the inverter can be calculated according to the following design equations derived in [6], [36]

$$
\begin{gathered}
C_{1}=\frac{1}{5.447 \omega R_{T}} \\
C_{2}=\frac{1}{\omega^{2} L_{T}}\left(1+\frac{1.42}{\frac{\omega L_{T}}{R_{T}}-2.08}\right) \\
P_{O}=0.5768 \frac{V_{I}^{2}}{R_{T}}
\end{gathered}
$$

where $C_{1}$ represents the total capacitance in parallel with the MOSFET and $C_{2}$ represents the total series capacitance.

Since Class E inverters are considered as resonant inverters, they operate optimally at a certain load value. Any variations in 


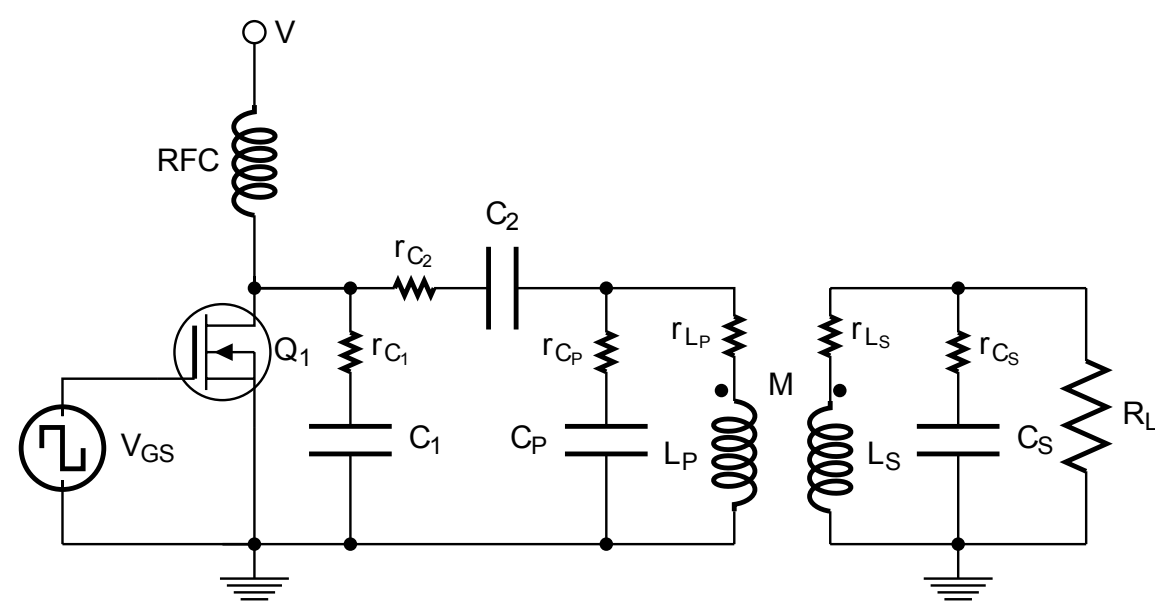

Fig. 7. The Class E inverter circuit diagram including coupled coils

the load from its optimum value will cause the Class E inverter to operate inefficiently as discussed in [16]. Figure 8 shows the simulated waveforms of the MOSFET's drain to source voltage and the drain current in a Class E inverter designed to drive the inductive link mentioned in Sec. II-D. The complete list of parameters and values of the Class E inverter are shown in Table. I. In Fig. 8a, the inverter is operating at its optimum switching conditions achieving ZVS and ZVDS. In Fig. 8b, the distance between the coils is increased which corresponds to a lower coupling coefficient, causing the reflected impedances to be reduced. In this case, the MOSFET switches ON at a negative voltage causing its body diode to conduct resulting in an inefficient operation. In Fig. 8c, the coils are brought closer to each other which corresponds to a higher coupling coefficient, the reflected impedances are now increased. The MOSFET in this case switches $\mathrm{ON}$ at a positive voltage causing a large current to flow through in its drain channel. The initial current that flows in the drain channel can surpass the MOSFET's maximum ratings and may cause irreversible damage.

\section{B. Electronic Tuning}

In order to allow the Class E inverter to cope with any variations in the reflected impedance due to a change in the load or the mutual inductance between the coils, the values of the inverter's main components and parameters such as $C_{1}$, $C_{2}$ and the switching frequency should be varied accordingly. For practical reasons, it is preferred that the reactances be varied electronically, i.e. including voltage or current dependant reactances rather than a mechanically adjustable component. Due to the large voltages and current values that are present in the Class $\mathrm{E}$ inverter circuit, a convenient technique to create a voltage or current dependant reactance is to use saturable reactors [42]. Figure 9 shows the Class E inverter including a saturable reactor $L_{S a t}$ connected in parallel with capacitor $C_{1}$. The capacitor connected in series with the saturable reactor is a DC blocking capacitor. By varying the reactance of the saturable reactor and the switching frequency, the effective reactance of $C_{1}$ can be changed to achieve the optimal switching conditions of the Class E inverter after a change in the reflected impedance occurs.

The proposed tuning method involves varying $L_{S a t}$ and the switching frequency only while keeping $C_{2}$ at a fixed value. Since the switching frequency is varied, the secondary coil will not be operating at resonance, instead it will be operating at near resonance as described in Sec. II-C. The required switching frequency and the value of capacitance $C_{1}$ are calculated by setting $C_{2}$ as a constant in Eq. 20 and solving for the frequency. The following equation is produced

$$
L_{T}^{2} C_{2}-2.08 \omega^{2} R_{T} L_{T} C_{2}-\omega L_{T}+0.66 R_{T}=0 .
$$

Equation 22 is solved numerically and the value of the required capacitance $C_{1}$ is calculated from Eq. 19. Figure 10 shows the required values of capacitance $C_{1}$ and switching frequency to achieve optimum switching conditions as a function of the load resistance and the coupling coefficient. Since the reflected impedances are also a function of the switching frequency, infinite combinations of load resistances, coupling coefficient values and switching frequencies exist that can have an equal reflected impedance.

\section{EXPERIMENTAL VERIFICATION}

\section{A. Hardware Setup}

The circuit of the Class E inverter shown in Fig. 9 was constructed with values and parameters shown in Table. I. $Q_{1}$ is a STP40NF10 MOSFET from STMicroelectronics driven via an EL7154 MOSFET driver from Intersil. The circuit layout and component placement were designed to minimise the effects of parasitic elements on the operation of the inverter. The circuit configuration of the saturable reactor $L_{S a t}$ is shown in Fig. 11. The saturable reactor consists of two toroidal transformers connected in series with each other. Their primary windings are connected in phase, whereas their secondary or control windings connected in an antiphase manner to cancel the voltage induced by the current in the primary windings. The two toroids are wound on a TX22/14/6.4-3C90 ferromagnetic core from Ferroxcube which has a specified effective cross section area $A e$ of $24.8 \mathrm{~mm}^{2}$, an effective magnetic path length Le of $54.2 \mathrm{~mm}$, a relative permeability $U e$ of 2300 and an 


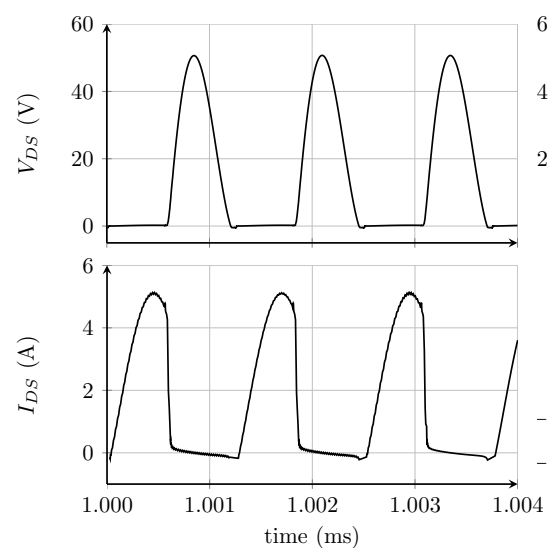

(a) $\mathrm{k}=0.05$ optimum operation

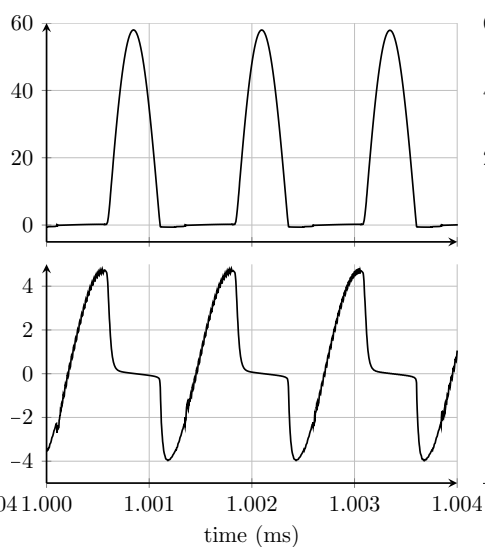

(b) $\mathrm{k}=0.01$ coils further apart

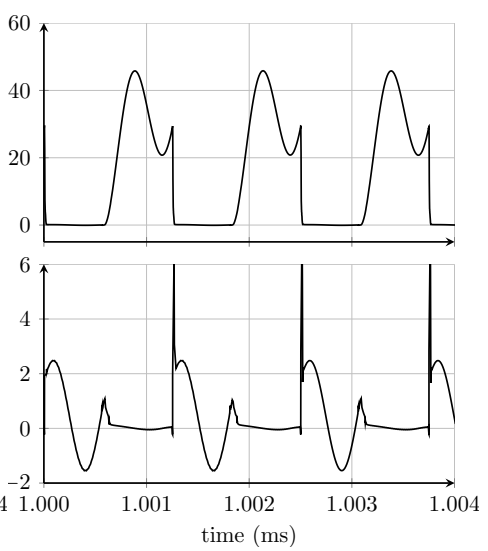

(c) $\mathrm{k}=0.075$ coils closer

Fig. 8. Effect of changing the distance between the primary and secondary coils on the performance of the inverter

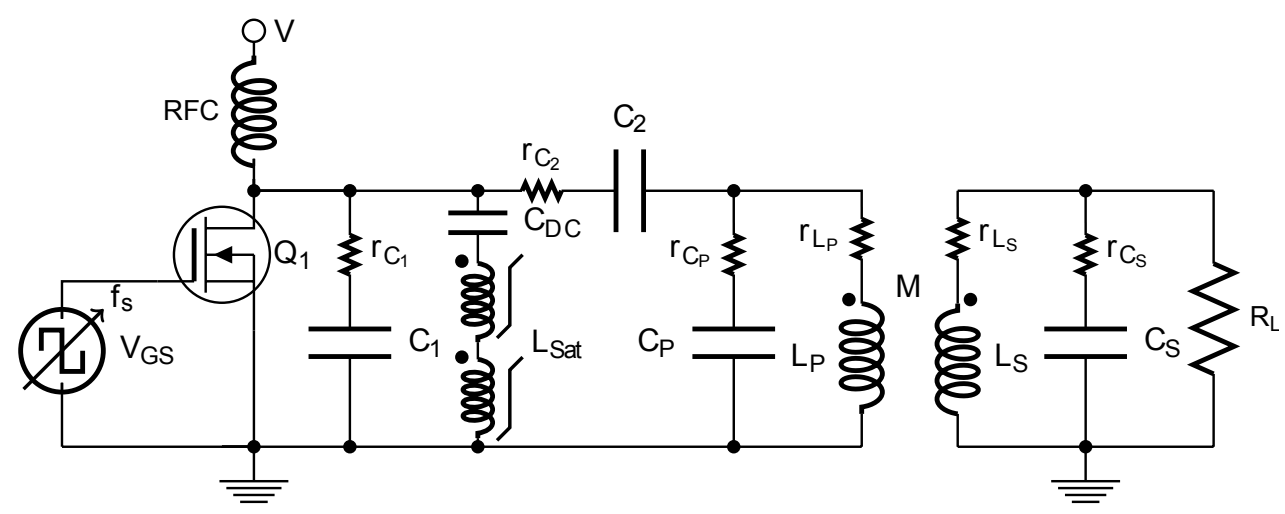

Fig. 9. The Class E inverter including a saturable reactor for tuning

inductance factor $\mathrm{Al}$ of $1400 \mathrm{nH} / \mathrm{Turn}^{2}$. The control windings of both toroids consist of 50 turns giving a total inductance of $6.6 \mathrm{mH}$ and the primary windings consist of 3 turns giving a total inductance of $25.2 \mu \mathrm{H}$ for each toroid. The DC control current $\left(I_{C}\right)$ applied to the control windings ranges from $0 \mathrm{~mA}$ for maximum inductance to $500 \mathrm{~mA}$ for minimum inductance. Due to the low inductance and low number of turns of the primary windings, it can be assumed that the current flowing in the primary windings will not cause the magnetic core to saturate. Figure 12 shows the measured effective capacitance of $C_{1}$ when the saturable reactor is connected in parallel with it as a function of the DC control current. Hysteresis is observed since the core of the saturable reactor is ferromagnetic. A photograph of the complete WPT system is shown in Fig. 13. The chosen values of the inverter allow it to operate in optimum switching conditions with $180 \mathrm{~mA} I_{C}$ for a load of $1 \mathrm{k} \Omega$ at a distance of $12 \mathrm{~cm}$ corresponding to a coupling coefficient of 0.035 .

\section{B. Results and Discussion}

To test the dependence of the Class $\mathrm{E}$ inverter on the reflected impedances, the distance between the coils is decreased from $12 \mathrm{~cm}$ to $5 \mathrm{~cm}$ in $1 \mathrm{~cm}$ steps for three different load values $470 \Omega, 1 \mathrm{k} \Omega$ and $2 \mathrm{k} \Omega$. For every step the Class E
TABLE I

VALUES AND RANGES OF SEVERAL PARAMETERS OF THE ClaSS E INVERTER AND THE INDUCTIVE LINK MEASURED AT $800 \mathrm{KHz}$

\begin{tabular}{|c|c|c|c|c|}
\hline \multirow{10}{*}{ 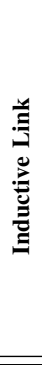 } & Component/Parameter & Value & ESR & Value \\
\hline & $L_{P}$ & $5.76 \mu \mathrm{H}$ & $r_{L_{P}}$ & $0.17 \Omega$ \\
\hline & $L_{S}$ & $6.69 \mu \mathrm{H}$ & $r_{L_{S}}$ & $0.28 \Omega$ \\
\hline & $C_{S}$ (Polypropylene) & $5.91 \mathrm{nF}$ & $r_{C_{S}}$ & $0.25 \Omega$ \\
\hline & $R_{L}$ Range & $0-2 \mathrm{k} \Omega$ & - & - \\
\hline & Frequency Range & $0.1-1 \mathrm{MHz}$ & - & - \\
\hline & Mutual Inductance $(M)$ Range & $0.17-1.73 \mu \mathrm{H}$ & - & - \\
\hline & Coupling Coefficient $(k)$ Range & $0.02-0.1$ & - & - \\
\hline & Distance Range & $2.5-15 \mathrm{~cm}$ & - & - \\
\hline & Resonant Frequency $f_{o}$ & $800 \mathrm{kHz}$ & - & - \\
\hline \multirow{12}{*}{ 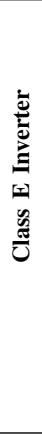 } & Component/Parameter & Value & ESR & Value \\
\hline & Input Voltage & $15 \mathrm{~V}$ & - & - \\
\hline & RFC & $200 \mu \mathrm{H}$ & $r_{R F C}$ & $0.25 \Omega$ \\
\hline & $C_{1}$ (Polypropylene) & $24 \mathrm{nF}$ & $r_{C_{1}}$ & $0.35 \Omega$ \\
\hline & $C_{2}$ (Polypropylene) & $5.34 \mathrm{nF}$ & $r_{C_{2}}$ & $0.3 \Omega$ \\
\hline & $C_{P}$ (Polypropylene) & $2.3 \mathrm{nF}$ & $r_{C_{P}}$ & $0.35 \Omega$ \\
\hline & $C_{D C}$ (Polypropylene) & $0.47 \mu \mathrm{F}$ & $r_{D C}$ & $0.35 \Omega$ \\
\hline & $L_{\text {Sat }}$ & $25.2+25.2 \mu \mathrm{H}$ & $r_{\text {Sat }}$ & $0.05 \Omega$ \\
\hline & Resonant Frequency $f_{o}$ & $800 \mathrm{kHz}$ & - & - \\
\hline & Switching Frequency Range $f_{s}$ & $790-845 \mathrm{kHz}$ & - & - \\
\hline & DC Control Range $I_{C}$ & $0-500 \mathrm{~mA}$ & - & - \\
\hline & Duty Cycle & $47 \%$ & - & - \\
\hline
\end{tabular}




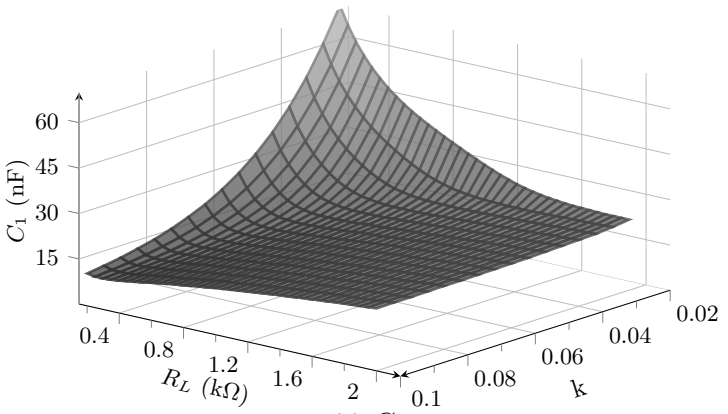

(a) $C_{1}$

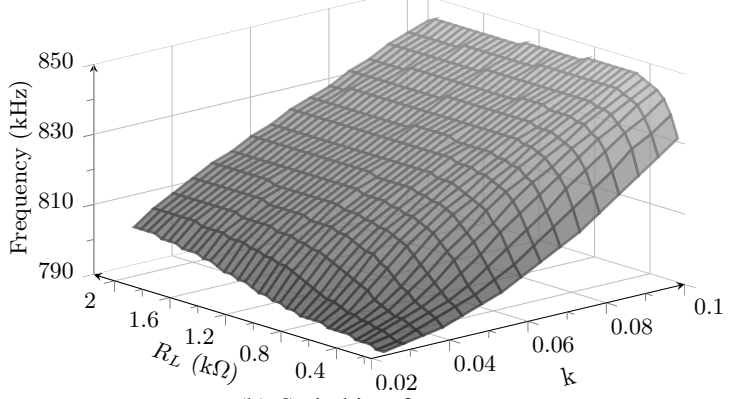

(b) Switching frequency

Fig. 10. $C_{1}$ and switching frequency variation as a function of the load resistance and coupling coefficient

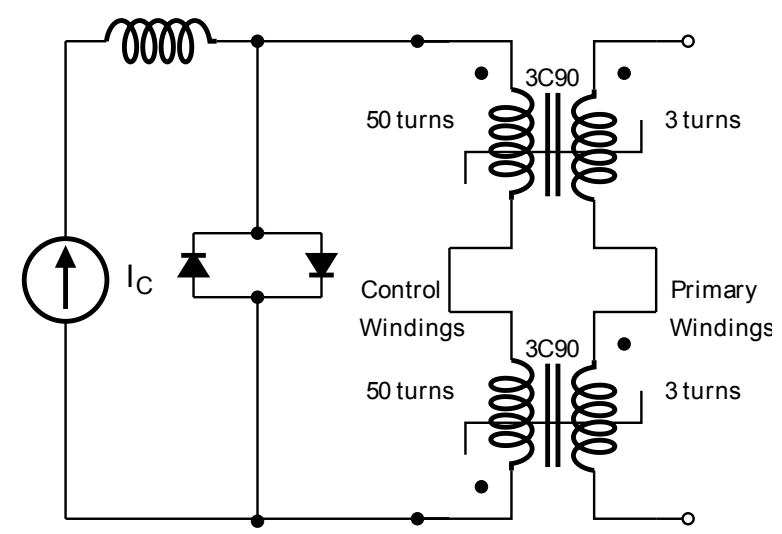

Fig. 11. Saturable reactor circuit configuration

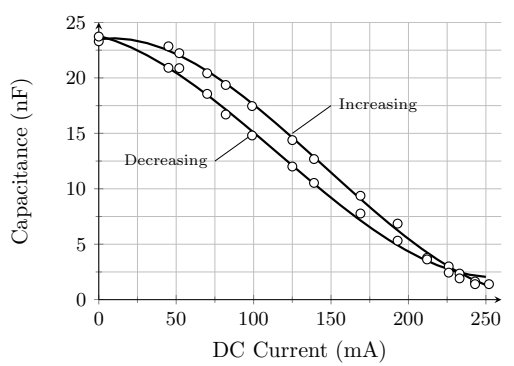

Fig. 12. The measured variation of Capacitance $C_{1}$ at $800 \mathrm{kHz}$ as a function of the saturable reactor's DC current applied to its control windings

inverter was retuned to achieve optimum switching conditions by adjusting the frequency and the saturable reactor's DC current. Figures 14 and 15 show the measured power received to the loads and the overall efficiency respectively. Simulation

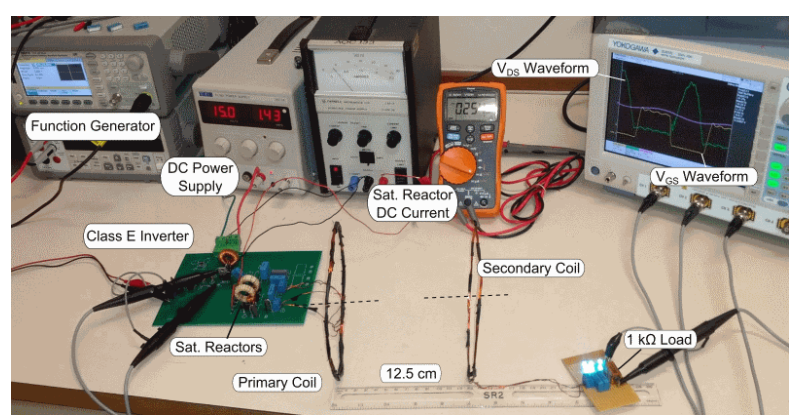

Fig. 13. Experimental setup of the WPT system

results obtained in SPICE are included for comparison. The Class E inverter is able to operate over a larger coil separation distance for lower loads with less variation in received power. The overall efficiency of the WPT system includes that of the MOSFET driver, the Class E inverter, the saturable reactor's primary coil and the inductive link. The efficiency is maintained at a relatively constant level for lower loads but at reduced values. Discrepancies between the simulated and measured results are mainly due to the instability of the passive components' tolerance to large current values and temperature variations.

Figures 16 and 17 show the switching frequencies and the saturable reactor's DC current that were required to achieve optimum operation for each step. Both are a linear function of distance or the coupling coefficient as predicted in Fig. 10. The difference between the calculated switching frequencies and the required switching frequencies is mainly due to the unaccounted nonlinear operation of the saturable reactor's primary windings. Although the control windings of the saturable reactor are connected in antiphase, the imperfection of the windings will cause a certain amount of voltage to be induced in the control windings. Therefore more DC current was injected to achieve the required effective capacitance compared to what was initially measured in Fig. 12.

Figure 18 shows the waveforms $V_{D S}$ and $V_{G S}$ of the Class E inverter for three different coil separation distances with a constant load resistance of $1 \mathrm{k} \Omega$. Figure 18 a shows the inverter working in optimal switching conditions at a distance of $12 \mathrm{~cm}$ without requiring any tuning $\left(I_{C}=180 \mathrm{~mA}\right)$ at a frequency of $800 \mathrm{kHz}$. In Fig. 18, the distance between the coil is decreased to $5 \mathrm{~cm}$. It can be observed that the Class E inverter is operating in a non-optimal switching condition since the MOSFET is now being switched $\mathrm{ON}$ at a non-zero drain voltage. The gate voltage $V_{G S}$ is distorted due to the high current spike that occurs once the MOSFET switches ON. In Fig. 18c, the saturable reactor's DC current was increased to $370 \mathrm{~mA}$ and the frequency was increased to $826 \mathrm{kHz}$. It can be noticed that the Class E inverter is now operating at optimal switching conditions. Therefore the tuning method described in Sec. III-B has been successfully validated.

\section{CONCLUSiOnS AND Future WORK}

In this paper, an improved circuit model of inductive links has been presented by including the ESR of the components of 


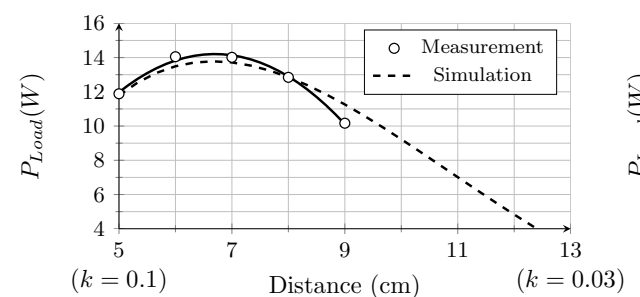

(a) $R_{L}=470 \Omega$

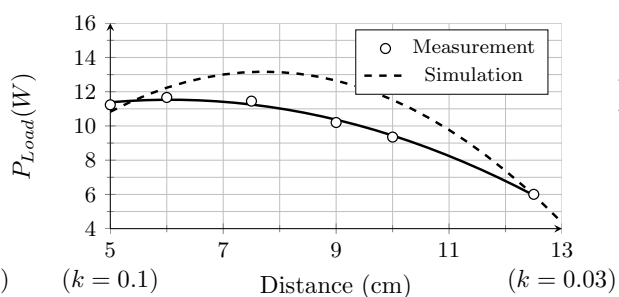

(b) $R_{L}=1 \mathrm{k} \Omega$

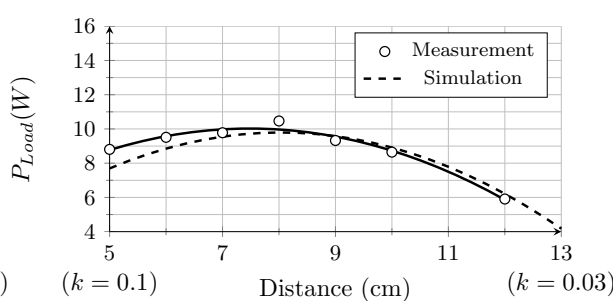

(c) $R_{L}=2 \mathrm{k} \Omega$

Fig. 14. Received power against coil separation distance for three different load values

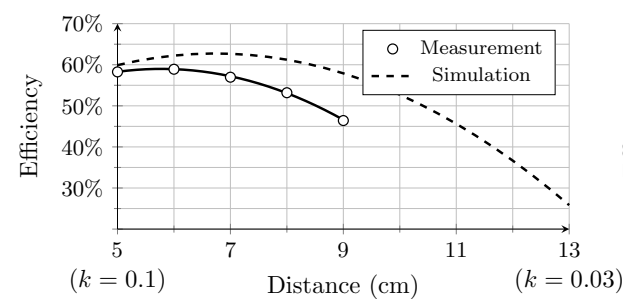

(a) $R_{L}=470 \Omega$

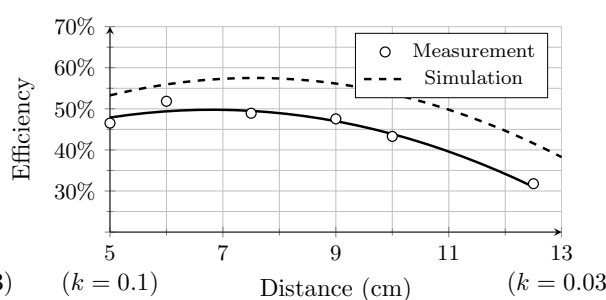

(b) $R_{L}=1 \mathrm{k} \Omega$

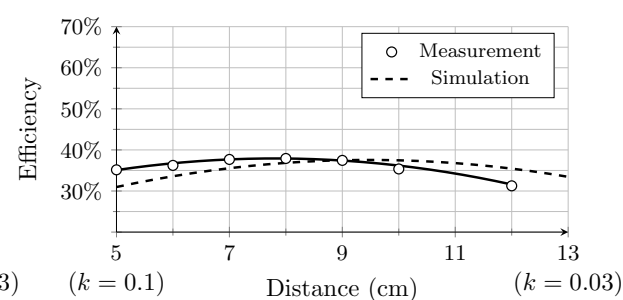

(c) $R_{L}=2 \mathrm{k} \Omega$

Fig. 15. Overall efficiency against coil separation distance for three different load values

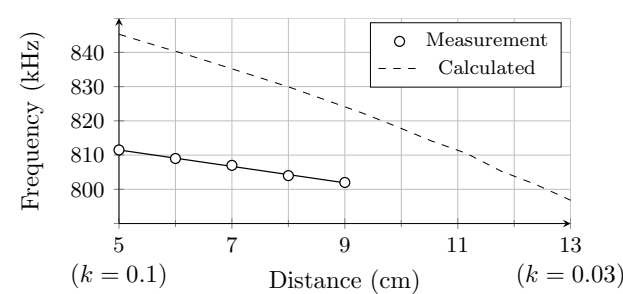

(a) $R_{L}=470 \Omega$

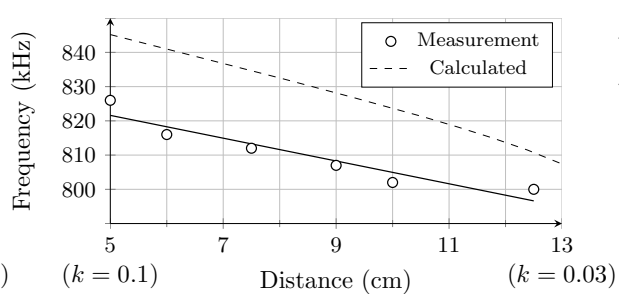

(b) $R_{L}=1 \mathrm{k} \Omega$

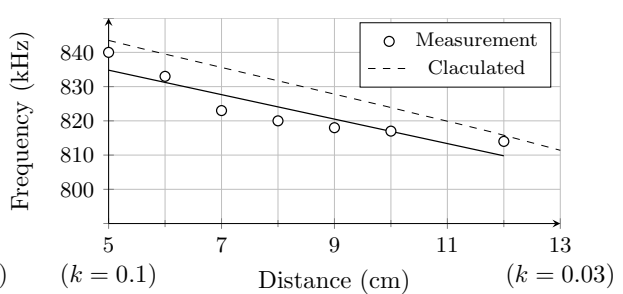

(c) $R_{L}=2 \mathrm{k} \Omega$

Fig. 16. Switching frequency against coil separation distance for three different load values

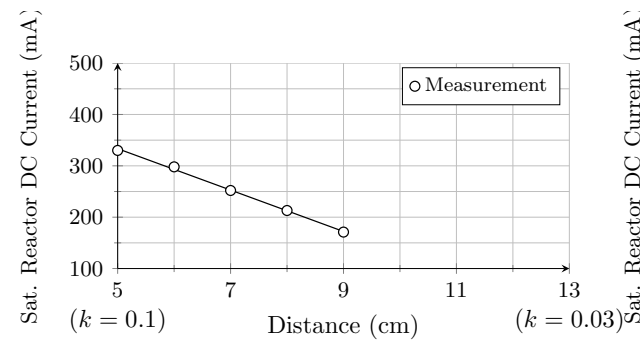

(a) $R_{L}=470 \Omega$

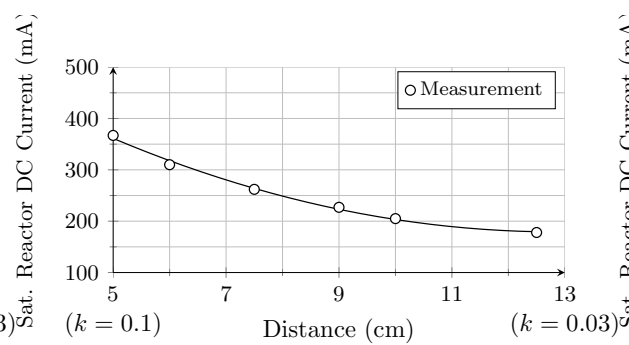

(b) $R_{L}=1 \mathrm{k} \Omega$

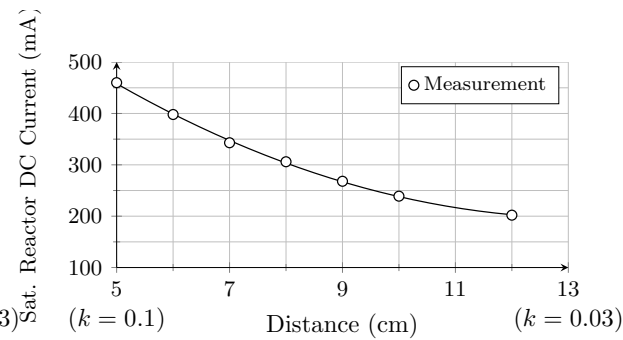

(c) $R_{L}=2 \mathrm{k} \Omega$

Fig. 17. Saturable reactors' DC current against coil separation distance for three different load values

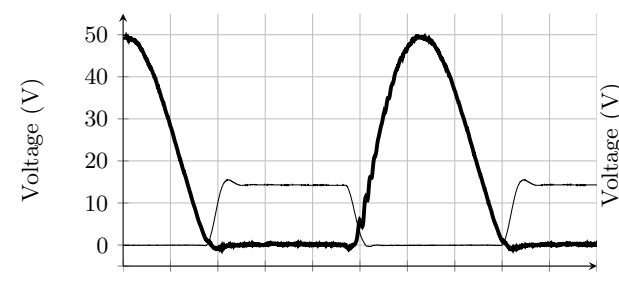

Time (200ns/div)

(a) Optimum switching operation at $12 \mathrm{~cm}$

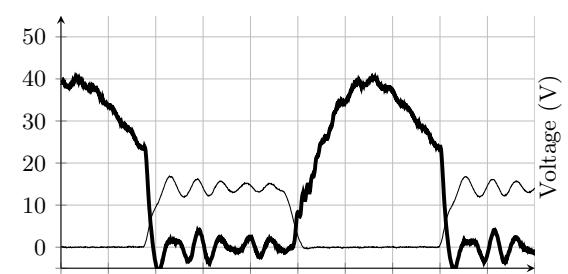

Time (200ns/div)

(b) Untuned non-optimum switching at operation at $5 \mathrm{~cm}$

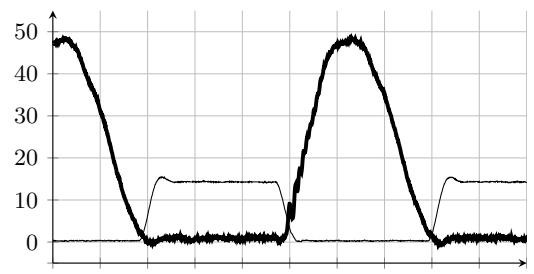

Time (200ns/div)

(c) Tuned optimum switching at $5 \mathrm{~cm}$

Fig. 18. Class E inverter waveforms according variation in coil separation distance ( $V_{D S}$ in bold and $V_{G S}$ in light lines respectively) 
the secondary coil circuitry into consideration. In the analysis performed, the reflected impedance of the load is isolated from the reflective impedance due to the ESR of the secondary coil and the resonant capacitor in a parallel resonant secondary coil configuration. This approach identifies which factors and parameters allow more power levels to be delivered to the load at higher efficiencies. Experimental results are presented to verify the analysis of the improved model.

The performance of Class E inverters used in inductive links is investigated. It is shown that the load resistance value and the coupling coefficient between the coils significantly affect the switching conditions of the inverter. A novel method to electronically tune the inverter to achieve optimum switching conditions by using a saturable reactor has been proposed. By varying the saturable reactor's DC current, the effective reactance of the capacitor in parallel with the switching MOSFET is altered. The performance and operation of the proposed tuning method is investigated as the load resistance and the coupling coefficient vary. The obtained experimental results verify the improved circuit model of inductive links and show the successful operation of the proposed tuning method.

For future work, since manual tuning was used to achieve optimum switching conditions as the load or coupling coefficient change, controllers and tuning algorithms could be developed to achieve automatic tuning. Additional modelling may include the effect and behaviour of saturable and nonlinear inductors in Class $\mathrm{E}$ inverters.

\section{REFERENCES}

[1] R. R. Harrison, "Designing efficient inductive power links for implantable devices," in IEEE Int. Symp. on Circuits and Systems (ISCAS), May 2007, pp. $2080-2083$.

[2] K. V. Schuylenbergh and R. Puers, Inductive Powering: Basic Theory and Application to Biomedical Systems. New York: Springer-Verlag, Jul. 2009.

[3] H. Wu, G. Covic, J. Boys, and D. Robertson, "A series-tuned inductivepower-transfer pickup with a controllable AC-voltage output," IEEE Trans. Power Electron., vol. 26, no. 1, pp. 98-109, Jan. 2011.

[4] M. Budhia, G. Covic, and J. Boys, "Design and optimization of circular magnetic structures for lumped inductive power transfer systems," IEEE Trans. Power Electron., vol. 26, no. 11, pp. 3096-3108, Nov. 2011.

[5] J. Huh, S. Lee, W. Lee, G. Cho, and C. Rim, "Narrow-width inductive power transfer system for online electrical vehicles," IEEE Trans. Power Electron., vol. 26, no. 12, pp. 3666-3679, Dec. 2011.

[6] N. O. Sokal and A. D. Sokal, "Class E-a new class of high-efficiency tuned single-ended switching power amplifiers," IEEE J. Solid-State Circuits, vol. 10, no. 3, pp. 168 - 176, Jun. 1975.

[7] Z. N. Low, R. A. Chinga, R. Tseng, and J. Lin, "Design and test of a high-power high-efficiency loosely coupled planar wireless power transfer system," IEEE Trans. Ind. Electron., vol. 56, no. 5, pp. 1801 1812, May 2009.

[8] G. A. Kendir, W. Liu, G. Wang, M. Sivaprakasam, R. Bashirullah, M. S. Humayun, and J. D. Weiland, "An optimal design methodology for inductive power link with class-E amplifier," IEEE Trans. Circuits Syst. I, Reg. Papers, vol. 52, no. 5, pp. 857 - 866, May 2005.

[9] M. V. Paemel, "High-efficiency transmission for medical implants," IEEE Solid State Circuits Mag., vol. 3, no. 1, pp. 47 - 59, Jan. 2011.

[10] E. M. Thomas, J. D. Heebl, C. Pfeiffer, and A. Grbic, "A power link study of wireless non-radiative power transfer systems using resonant shielded loops," IEEE Trans. Circuits Syst. I, Reg. Papers, vol. 59, no. 9, pp. 2125 - 2136, Sept. 2012.

[11] J. J. Casanova, Z. N. Low, and J. Lin, "Design and optimization of a class-E amplifier for a loosely coupled planar wireless power system," IEEE Trans. Circuits Syst. II, Exp. Briefs, vol. 56, no. 11, pp. 830 834, Nov. 2009.
[12] N. Kim, K. Kim, J. Choi, and C.-W. Kim, "Adaptive frequency with power-level tracking system for efficient magnetic resonance wireless power transfer," Electron. Lett., vol. 48, no. 8, pp. 452 - 454, 122012.

[13] H. Taghavi, B. Håkansson, and S. Reinfeldt, "Analysis and design of rf power and data link using amplitude modulation of class-E for a novel bone conduction implant," IEEE Trans. Biomed. Eng., vol. 59, no. 11, pp. 3050 - 3059, Nov. 2012.

[14] M. Pinuela, D. C. Yates, S. Lucyszyn, and P. D. Mitcheson, "Maximizing DC-to-load efficiency for inductive power transfer," IEEE Trans. Power Electron., vol. 28, no. 5, pp. 2437 - 2447, May 2013.

[15] D. Murthy-Bellur, A. Bauer, W. Kerin, and M. Kazimierczuk, "Inverter using loosely coupled inductors for wireless power transfer," in IEEE 55th Int. Midwest Symp. on Circuits and Systems, 2012, pp. 1164-1167.

[16] F. H. Raab, "Effects of circuit variations on the class E tuned power amplifier," IEEE J. Solid-State Circuits, vol. 13, no. 2, pp. 239 - 247, Apr. 1978.

[17] M. K. Kazimierczuk and X. T. Bui, "Class-E amplifier with an inductive impedance inverter," IEEE Trans. Ind. Electron., vol. 37, no. 2, pp. 160 - 166, Apr. 1990.

[18] _ - "Class E DC/DC converters with an inductive impedance inverter," IEEE Trans. Power Electron., vol. 4, no. 1, pp. 124 - 135, Jan. 1989.

[19] K. Thomas, S. Hinchliffe, and L. Hobson, "Class E switching-mode power amplifier for high-frequency electric process heating applications," Electron. Lett., vol. 23, no. 2, pp. 80 - 82, 1987.

[20] Y. Han, O. Leitermann, D. A. Jackson, J. M. Rivas, and D. J. Perreault, "Resistance compression networks for radio-frequency power conversion," IEEE Trans. Power Electron., vol. 22, no. 1, pp. 41 - 53, Jan. 2007.

[21] D. Collins, S. Hinchliffe, and L. Hobson, "Optimised class-E amplifier with load variation," Electron. Lett., vol. 23, no. 18, pp. 973 - 974, 1987.

[22] M. Vasic, O. Garcia, J. A. Oliver, P. Alou, D. Diaz, R. Prieto, and J. A. Cobos, "Envelope amplifier based on switching capacitors for highefficiency RF amplifiers," IEEE Trans. Power Electron., vol. 27, no. 3, pp. 1359 - 1368, Mar. 2012

[23] R. Zulinski and K. Grady, "Load-independent class E power inverters i. theoretical development," IEEE Trans. Circuits Syst. I, Reg. Papers, vol. 37, no. 8, pp. 1010 - 1018, Aug. 1990.

[24] L. Roslaniec and D. Perreault, "Design of variable-resistance class E inverters for load modulation," in IEEE Energy Conversion Congress and Expo., Sept. 2012, pp. 3226 - 3232.

[25] Y.-F. Li, "Auto-tuning controller design of class E inverter with resonant components varying," in IEEE Int. Symp. on Industrial Electronics, May 2012, pp. $217-221$.

[26] R. C. N. Pilawa-Podgurski, A. D. Sagneri, J. M. Rivas, D. I. Anderson, and D. J. Perreault, "Very-high-frequency resonant boost converters," IEEE Trans. Power Electron., vol. 24, no. 6, pp. 1654 - 1665, Jun. 2009.

[27] Z. Yang, W. Liu, and E. Basham, "Inductor modeling in wireless links for implantable electronics," IEEE Trans. Magn, vol. 43, no. 10, pp. 3851 - 3860, Oct. 2007.

[28] L. Chen, S. Liu, Y. C. Zhou, and T. J. Cui, "An optimizable circuit structure for high-efficiency wireless power transfer," IEEE Trans. Ind. Electron., vol. 60, no. 1, pp. 339 - 349, Jan. 2013.

[29] H. Matsumoto, Y. Neba, K. Ishizaka, and R. Itoh, "Model for a threephase contactless power transfer system," IEEE Trans. Power Electron., vol. 26 , no. 9 , pp. 2676 - 2687, Sept. 2011.

[30] - "Comparison of characteristics on planar contactless power transfer systems," IEEE Trans. Power Electron., vol. 27, no. 6, pp. $2980-$ 2993, Jun. 2012.

[31] W. Zhong, C. K. Lee, and S. Hui, "General analysis on the use of Tesla's resonators in domino forms for wireless power transfer," IEEE Trans. Ind. Electron., vol. 60, no. 1, pp. 261 - 270, Jan. 2013.

[32] J. Mur-Miranda, G. Fanti, Y. Feng, K. Omanakuttan, R. Ongie, A. Setjoadi, and N. Sharpe, "Wireless power transfer using weakly coupled magnetostatic resonators," in IEEE Energy Conversion Congr. and Expo. (ECCE), Sept. 2010, pp. $4179-4186$.

[33] A. Kurs, A. Karalis, R. Moffatt, J. D. Joannopoulos, P. Fisher, and M. Soljacic, "Wireless power transfer via strongly coupled magnetic resonances," Science, vol. 317, no. 5834, pp. 83 - 86, 2007.

[34] R. Jegadeesan and Y.-X. Guo, "Topology selection and efficiency improvement of inductive power links," IEEE Trans. Antennas Propag., vol. 60 , no. 10 , pp. 4846 - 4854, Oct. 2012.

[35] M. Kazimierczuk and K. Puczko, "Exact analysis of Class-E tuned power amplifier at any $\mathrm{Q}$ and switch duty cycle," IEEE Trans. Circuits Syst., vol. 34, no. 2, pp. 149-159, Feb. 1987.

[36] M. K. Kazimierczuk, RF Power Amplifiers. Chichester, UK: John Wiley \& Sons, 2008. 
[37] M. K. Kazimierczuk and D. Czarkowski, Resonant Power Converters, 2nd ed. New Jersey, USA: John Wiley \& Sons, 2011.

[38] D. Kessler and M. Kazimierczuk, "Power losses and efficiency of ClassE power amplifier at any duty ratio," IEEE Trans. Circuits Syst. I, Reg. Papers, vol. 51, no. 9, pp. 1675-1689, Sep. 2004.

[39] T. Suetsugu and M. Kazimierczuk, "Design procedure of Class-E amplifier for off-nominal operation at 50\% duty ratio," IEEE Trans. Circuits Syst. I, Reg. Papers, vol. 53, pp. 1468-1476, Jul. 2006.

[40] - "Off-nominal operation of Class-E amplifier at any duty ratio," Circuits and Systems I: Regular Papers, IEEE Transactions on, vol. 54, no. 6, pp. 1389-1397, Jun. 2007.

[41] _ "Analysis and design of Class-E amplifier with shunt capacitance composed of nonlinear and linear capacitances," IEEE Trans. Circuits Syst. I, Reg. Papers, vol. 51, no. 7, pp. 1261-1268, Jul. 2004.

[42] M. K. Kazimierczuk, High-Frequency Magnetic Components. West Sussex, UK: John Wiley \& Sons, 2009.

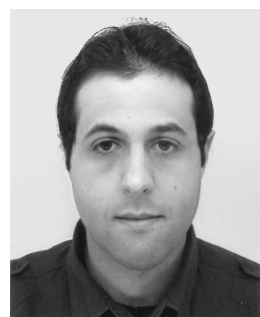

Samer Aldhaher received the B.Sc. degree in electrical engineering from the University of Jordan, Amman, Jordan in 2010. He is currently working towards the Ph.D. degree at Cranfield University, Bedford, UK.

His current research interests include the design of high frequency DC/AC inverters, wireless power transfer applications based on resonant inductive links and switched-mode circuits.

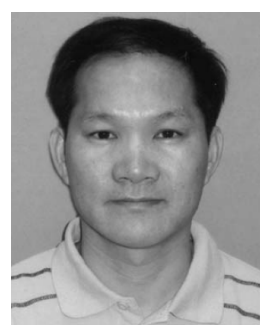

Patrick Chi-Kwong Luk (M'92-SM'08) was born in Hong Kong. He received the High Diploma with merits (BSc) in electrical engineering from Hong Kong Polytechnic University, Hong Kong, in 1983, the M.Phil. degree in electrical engineering from Shefeld University, U.K., in 1989, and the Ph.D degree in electrical engineering from the University of South Wales in 1992.

He started his career in industry in 1983, first as an Assistant Engineer at GEC (H.K.) and then as an Application Engineer at Polytek Engineering Co. (H.K.). In 1986, he became a Researcher with the Industrial Centre, PolyU. Since 1988, he has held academic positions at the University of South Wales, Robert Gordon University, Aberdeen, U.K., and University of Hertfordshire, U.K. He joined Craneld University, Shrivenham, U.K., in 2002 , where he is currently the head of the Electric Power and Drives Group, School of Engineering. Currently he is the Chairman of the IEEE UK\&RI Power Electronics Chapter. He has published over 130 technical papers and co-holder of several patents in power electronics, motor drives, and control. His main current research interests include electrical drives for electric vehicles and renewable energy applications, and high-frequency ac power distributions.

He won the 2011 IET Premium Award in Electric Power Applications.

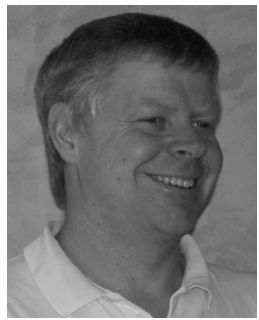

James F. Whidborne (M'95-SM'10) received the $\mathrm{BA}$ in engineering from Cambridge University and $\mathrm{MSc}$ and $\mathrm{PhD}$ in systems and control from University of Manchester Institute of Science and Technology (UMIST), UK.

From 1991-1994, he was a research associate with the Department of Engineering, University of Leicester. From 1994-2003, he was a lecturer, then senior lecturer with the Department of Mechanical Engineering, Kings College London. He is currently Head of the Dynamics Simulation and Control Group in the Department of Aerospace Engineering at Cranfield University, UK. His research interests are in the theory and application of advanced control, including multi-objective robust control design, fluid flow control, finite precision controller implementation problems, as well as flight control problems such as control and guidance of UAVs, controller reallocation and attitude control of VTOL aircraft.

$\mathrm{He}$ is a chartered engineer, a Member of the IET and a Senior Member of the IEEE. 